\title{
Biomedical Waste Management
}

\author{
MT MIAH, A RASHED
}

Health care activities are targeted to save lives; at the same time, itgeneratespotentially infectious or biohazardous waste. Biomedical waste (BMW) is a special type of waste generated during any medical procedures, may be directly from patient care or biomedical laboratory works. Of the total amount of waste generated by health-care activities, about $15-20 \%$ is considered hazardous material that may be infectious, toxic or radioactive. ${ }^{1}$ But this small amount of hazardous waste may complicate the whole scenario if not segregated at source. In middle and low-income countries, healthcare waste generation is usually lower than that of high-income countries. ${ }^{2}$ When segregated and properly managed, medical waste streams are usually very small in quantity. ${ }^{3}$ Improper disposal of medical waste may include damage to humans by sharp instruments, diseases transmitted to humans by infectious agents, and contamination of the environment by toxic and hazardous chemicals. The management of health-care waste requires increased attention and diligence to avoid adverse health outcomes associated with poor practice, including exposure to infectious agents and toxic substances.

The basic principle of BMW management is segregation at source and waste reduction.Initial segregation prevents the contamination of vast majority of non-hazardous waste while waste reduction eases the final disposal ensuring environment safety. The basic principle of good BMW practice is based on the concept of 3Rs, namely, reduce, recycle, and reuse. ${ }^{4}$ With advancement and better penetration of health care facilities there is huge increase in BMW. In developed countries $1-5 \mathrm{Kg}$ waste is generated per patient daily which is nearly half in our country with a value of $0.8-1.67 \mathrm{Kg} / \mathrm{patient} /$ day. The yearly BMW produced in Dhaka city alone is 93,075 tons which is increasing daily. ${ }^{5}$

World Health Organization provides guideline for all hospitals to comply with in order to ensure safe medical waste management. These are (a) Waste Minimization at source by reuse, recover and stock management; (b) Waste Segregation by categories and sharps; (c) Waste Identification by colour coding for different wastes; (d) Waste Collection and storage by routine programme; (e) Waste Transfer by following "chalked Path way from generation to disposal sites and use enclosed vehicle (f) Treatment Option by both burn and non-burn ways.

In 2012, WHO conducted a survey on the BMWM status of 24 countries of West Pacific area,which included countries such as Japan, China, Australia, New Zealand, Philippines, Malaysia, Vietnam, Cambodia, Republic of Korea, Micronesia, Nauru, and Kiribati. It was found that most of the countries had no or very less financial resources for BMW management. ${ }^{6}$

Biomedical waste is a threat to global public environmental health, especially in the lower-middle-income countries such as Bangladesh. Worldwide, it is estimated that at least $5 \cdot 2$ million people, including 4 million children, die each year because of diseases related to unmanaged medical waste. ${ }^{7}$ Improper disposal of medical waste may cause damage to humans by sharp objects, diseases transmitted to humans by infectious agents, and contamination of the environment by toxic and hazardous chemicals.

Bangladesh has some 460 Upazilla level Hospitals and 9722 community level clinics and about 1449 outdoor health facilities at Union level that falls under DGHS. From the same study it was also found that at district level there are about 117 hospitals that are currently functioning. Among the private hospitals there are about 2501 registered hospitals and 5122 registered diagnostic Centre throughout the country. ${ }^{8}$ In addition, there are many clinics, including about 5000 government and NGO run clinics, and doctor's chambers where health care waste is generated. In Dhaka City alone there are about 1200 hospitals, clinics and diagnostic centres. ${ }^{9}$ In a Bangladeshi study it wasconcluded that medical waste is not managed properly in most of the hospitals of Bangladesh due to lack of proper guideline, commitment and training of the healthcare personnel.

In Bangladesh Ministry of Environment \&Forest passed the biomedical waste management and disposal rules in 2008. These rules elaborately state the formation of different committees with their responsibilities, classification of different biomedical waste \& their specific disposal methods, use of different color coding systems and symbols in waste management, instructions for organizations involvedin final disposal of biomedical waste ensuring environmental safety\& security and lastly penalties for breaching these rules.

Ministry of Health and Family Welfare (MoHFW) is working closely with Ministry of Local Government for proper disposal of hospital waste. BMW management activities were first included in 5 yearly 
HPSP of MoHFW in 1998 for hospitals providing secondary care and above. The Health ministryprepared an Environmental Assessment and Action Plan in HPNSDP 2011-16. DGHS \& DGFPtook necessary steps to form Infection Prevention \& Control Committee in all hospitals headed by the head of the organization to look after hospital waste management. Currently some NGOs are also working on this issue besides government.

Currently government is providing logistics only to public hospitals for BMW management. Private hospitals are required to stick to government rules on BMW management to obtain their operational license. Government of Bangladesh is implementing BMWM in association with NGOs. Currently 5 NGOs are working in different areas of the country for collection and final disposal of hospital waste. Among them only PRISM is applying all the methods of final disposal of BMW by incineration, autoclave and dumping. Other organizations only rely on dumping.

No specific data is found regarding the current status of biomedical waste management in Bangladesh. But from our experience we find waste management committee have been formed in many hospitals, color coded bins are in use, hospital wastes are disposed separately though not always in the right manner. But more action is needed to meet the standard.

Bangladesh is already struggling with poor medical waste management before the COVID-19 pandemic and has now been hit hard by a sudden increase in the volume of medical waste. The average medical waste generation rate is $1.63-1.99 \mathrm{~kg}$ per bed per day in Dhaka, the capital of Bangladesh. ${ }^{10}$ In April 2020, at least 14,500 tonnes of waste from health care was generated across the country because of COVID-19,4 which has undoubtedly increased due to the increasing infection rate. Also, on average, 206 tonnes of medical waste are produced because of COVID-19 per day in Dhaka alone. ${ }^{11}$ This poorly managed waste poses a large environmental threat and might create a prolonged and unwanted public health hazard and be a potential source of re-emerging infection.

Health care facilities in Bangladesh pose significant threat to health and environment on account of inadequate waste management. Proper waste management policy isrequired to ensure health and environmental safety. Simple changes in policy\& planningand support from government and collaboration between public \& private sectors would bring impactful changes in healthcare waste management. However, the healthcare waste management guideline, planning and policy should be under the shadow of legislation, emphasis should be given in the development of educational training programme, record keeping, monitoring, review of existing situation and there should be collaboration between different ministries, hospital authorities, and active participation from the community.

(J Bangladesh Coll Phys Surg 2020; 38: 158-159)

DOI: https://doi.org/10.3329/jbcps.v38i4.48974

\section{Md. Titu Miah}

Professor of Medicine \& Principal, Mugda Medical College

\section{Asif Rashed}

Assistant Professor of Microbiology, Mugda Medical College

\section{Reference:}

1. Li CS, Jenq FT. Physical and chemical composition of hospital waste. Infect Control HospEpidemiol. 1993;14:145-50.

2. WHO (World Health Organization). 2004 "Health-care Waste Management", policy paper, Department of Protection of the Human Environment Water, Sanitation and Health 20. Geneva 27, Switzerland

3. WHO (World Health Organization). 1999. Safe Management of Wastes from Health-Care Activities. Geneva.

4. Chartier Y, Emmanuel J, Pieper U, Prüss A, Rushbrook P, Stringer R, editors. 2nd. Geneva, Switzerland: WHO Press; 2014. Safe Management of Wastes from Health-Care Activities; pp. 1-146.

5. Rahman, A.K.M., (ed.), 2000, SituationAssessment and analysis of Hospital waste Management (A Piolt Study), Line Director, Hospital Services, DGHS, Dhaka

6. https://www.google.co.in/search?rlz=1C1RLNS_enIN $730 \mathrm{IN} 730 \& \mathrm{q}=\mathrm{WHO}+\mathrm{Bio}+$ medical + waste + west + pacific $\&$ $\mathrm{oq}=\mathrm{WHO}+$ Bio + medical + waste + west + pacific and gs $\mathrm{l}=\mathrm{psy}-\mathrm{ab}$ 3.4449.8925.0.9286.20.15.0.0.0.0.393.2252.2-6j2.8.0.0.1. 1.64.psy-ab.16.1.245.0i13k1j0i13i30k1.0.ymdTNBt-k68\#.

7. https://www.thedailystar.net/editorial/news/poor-medicalwaste-management-will-increase-infections-190956, Date: June 6, 2020

8. Secondary and Tertiary Health Care Facilities in Bangladesh 2010, (n.d) retrieve from:http://nasmis.dghs.gov.bd/dghs new/ dmdocuments/All/Secondary\%20and\%20Tertiary\%20Car e $\% 20$ Facilities.pdf

9. International Centre for Diarrhoeal Research, Bangladesh (ICDDR, B) 1997, An Interventory of health and Family Planning Facilities in Dhaka City, MCH-FP Extention Project (Urban), Health and Population Division, ICDDR, B

10. Rahman KA. Survey on quantitative and qualitative assessment of medical waste generation and management in Dhaka North City Corporation and Dhaka South City Corporation. PRISM Bangladesh. 2013. http://pbf.org. bd/wp-content/uploads/ 2014/01/Survey-on- Quantitativequalitativeassessment-ofmedical-waste-generation-andma nagemant-in-DNCC-DSCC.pdf

11. The Business Standard Report. 206 2 tonnes of COVID-19 wastes produced in Dhaka a day: study. The Business Standard. July 5, 2020. https://tbsnews.net/coronavirus-chronicle/ covid-19-bangladesh/206218-tonnes-covid19-wastes-prod uced-dhaka-day-study 